\title{
Repairing the damaged thyroid proteome through tailored supplementation with magnesium, selenium and coenzyme Q10: potential applicability for cardiac disease
}

\author{
Moncayo R*, Moncayo $H$ and Reisenzahn J \\ Department of Nuclear Medicine, Medical University of Innsbruck, Innsbruck, Austria
}

\begin{abstract}
The concept of a proteostasis network has been proposed as a general mechanism for maintaining cellular function and integrity. The network includes a series of biochemical elements, which require energy in the form of ATP. This aspect, however, has received little attention in scientific publications. The aim of this study was to demonstrate the efficacy of a combined supplementation protocol based on magnesium, selenium and Coenzyme Q10 (CoQ10) for thyroid disease. This approach can lead to normalization of thyroid morphology and perfusion, thus fulfilling the postulates of proteostasis. In the field of cardiology similar concepts have been used in clinical practice. Relying only on selenium and CoQ10 they have also demonstrated the beneficial effect as seen in patients with heart disease. In comparison to these results, a literature analysis of supplementation studies done with single substances, i.e. either selenium or CoQ10, reveals that specific endpoint criteria are not accurate. We conclude that a combined supplementation of selected elements - magnesium, selenium and CoQ0 - improves the proteostasis processes in the thyroid, i.e. thyroid morphology will normalize. Literature sources on a similar approach have shown beneficial effects on patients with heart disease. These data suggest a general applicability of the combined supplementation approach. We propose the concept of Shared Resources as a mechanism that delivers the basic elements magnesium, selenium and CoQ10 and also iron to different organs. Their interplay will support mitochondrial and endoplasmic reticulum function by maintaining ATP production and finally guarding proteostasis.
\end{abstract}

\section{Introduction}

Since many decades research efforts on aging and disease have been centered around concepts of oxidative damage caused by radicals originating outside of living organisms. An early study on this topic was presented by Gerschman in 1953 (published in 1954) [1]. Harman followed in 1956 with his aging theory [2]. In recent years the concepts of disease mechanisms have shifted towards proteostasis as proposed by Balch in 2008 [3]. The proteostasis concept encompasses a network of cellular biochemical components that are dedicated to keep a correct biological activity of the cells [4]. In the field of cardiology, Henning et al. are working on targeting protein quality control as a way to promote heart health [5]. In the field of thyroid diseases, the concept of autoimmunity has now been associated to the topic of cell stress, however no clear therapeutic ideas have emerged [6]. In cases of thyroid disease marked destruction of the structure of the gland can be found [7], thus demonstrating that proteostasis is compromised. Besides morphological changes, functional alterations can lead either to hypothyroidism or hyperthyroidism or both [8]. The most frequently discussed pathogenic mechanism for benign thyroid disease refers to alterations of the immune system [9]. Contrary to this belief, we have proposed that benign thyroid disease corresponds to an acquired mitochondria dysfunction due to specific biochemical deficiencies which affect blood levels of magnesium, selenium and Coenzyme Q10 (CoQ10) [10,11]. Our working hypothesis considers that this deficiency state will compromise ATP production. Low ATP supply in different organs could alter proteostasis processes [12]. Besides energy supply, ATP is also important as a biological hydrotrope agent which is important for cardiac function $[13,14]$.
In view of these circumstantial relationships we present here the therapeutic effects of tailored supplementation with magnesium, selenium and CoQ10 in cases of thyroiditis as well as in hyperthyroidism. Considering the importance of mitochondrial function in the field of cardiology [15]. we will include a short reference of studies dedicated to the treatment of heart disease based on the combination of selenium plus CoQ10. A short evaluation of supplementation studies using single substances, i.e. selenium or CoQ10, will also be included.

\section{Patients and methods}

Patients attending the out-patient thyroid service of the General Hospital in Innsbruck had been previously examined and treated by one of us (RM). Those patients who were classified as having a subacute thyroiditis or hyperthyroidism (Grave's disease) were retrieved for the retrospective evaluation. Hyperthyroid patients had received thyreostatic $(n=9)$ therapy plus supplementation while thyroiditis patients $(n=23)$ received only supplementation. Besides the initial visit, two follow-up consultations had been done in every case. Ultrasound examination of the thyroid was done with a LOGIQ E9 machine (General Electrics, GE Healthcare Austria, Zipf, Austria) using a 15

${ }^{\star}$ Correspondence to: Moncayo R, Department of Nuclear Medicine, Medical University of Innsbruck, WOMED, Innsbruck, Austria, E-mail: Roy. Moncayo@i-med.ac.at

Key words: thyroid disease, heart disease, magnesium, selenium, Coenzyme Q10, power Doppler sonography, proteostasis

Received: February 17, 2020; Accepted: March 02, 2020; Published: March 10, 2020 
$\mathrm{MHz}$ probe. Vascularization was demonstrated using power Doppler modus. Cases showing signs of fibrosis of the thyroid were not included in the evaluations since previous observations have shown no response to supplementation in these cases.

\section{Results}

Over a period of 18-24 months, signs of improved morphology and decreased vascularization were seen. In general, the morphological changes included a reduction of thyroid volume and a normalization of the structure of the gland in cases of subacute thyroiditis. Two representative clinical cases are shown in the figure 1. In hyperthyroidism the pattern of increased vascularization of the gland normalized during treatment (Figure 2). Thyroid morphology also showed improvement (Figure 3).

\section{Discussion}

This short paper confirms our previous experience related to a beneficial effect of a combined supplementation for patients with thyroid disease [10]. The difference to the previous study lies in the longer duration of treatment i.e. up to 2 years. The use of advanced sonography methods allows the definition of objective endpoints. On the other hand, studies that have relied on the single administration of selenium for thyroid disease have not been conclusive [16]. This situation has been addressed by Schomburg in 2011 by stating the following: "Some clinical studies have demonstrated that seleniumdeficient patients with autoimmune thyroid disease benefit from selenium supplementation, although the data are conflicting and many parameters must still be defined" [17].

Searching for similar therapy concepts, we came across the publications by the group of Alehagen et al. who has been successful in the treatment of patients with heart failure [18-25]. While we administer 30 to $60 \mathrm{mg}$ CoQ10 daily, Alehagen et al. prescribed 200mg daily. The dose of selenium is similar with $200 \mu \mathrm{g}$ daily. Magnesium administration is included only in our protocol. The current daily dose lies between 3 to $4 \mathrm{~g}$. of pure magnesium citrate dissolved in 500 to $750 \mathrm{ml}$ of water. Magnesium administration has the potential of being beneficial for patients with heart disease [26]. A Cochrane analysis of single administration of CoQ10 for patients for heart disease has concluded that there are no clinically relevant endpoints [27].

We conclude that proteostasis can be restored in the thyroid by instituting a combined supplementation protocol. The theory behind the interactions between magnesium, selenium and CoQ10 has been described elsewhere in this Journal (Citation Moncayo, Moncayo). Since the same elements have beneficial effects on different systems, we propose the concept of Shared Resources as a basic functional framework for cell physiology and proteostasis guarding the function of mitochondria and endoplasmic reticulum.

\section{Conflicts of interest}

The authors declare no conflicts of interest.

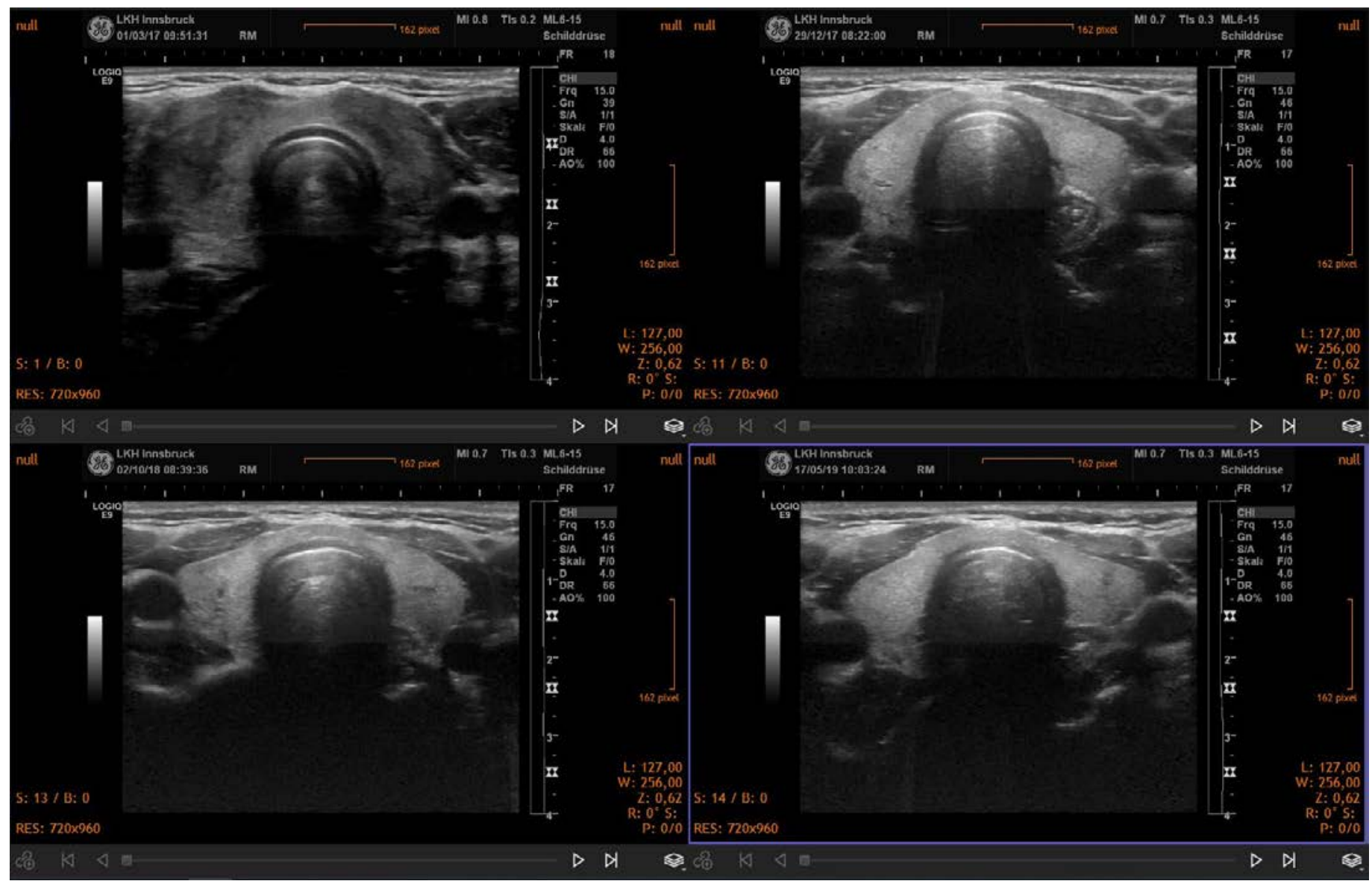

Figure 1. Sequential demonstration of normalization of thyroid morphology in a case of subacute thyroiditis. The initial study (upper left panel) revealed an inhomogeneous structure with many areas with reduced echogenicity. The final image (lower right panel) shows a normal thyroid morphology 
Moncayo R (2020) Repairing the damaged thyroid proteome through tailored supplementation with magnesium, selenium and coenzyme Q10: potential applicability for cardiac disease

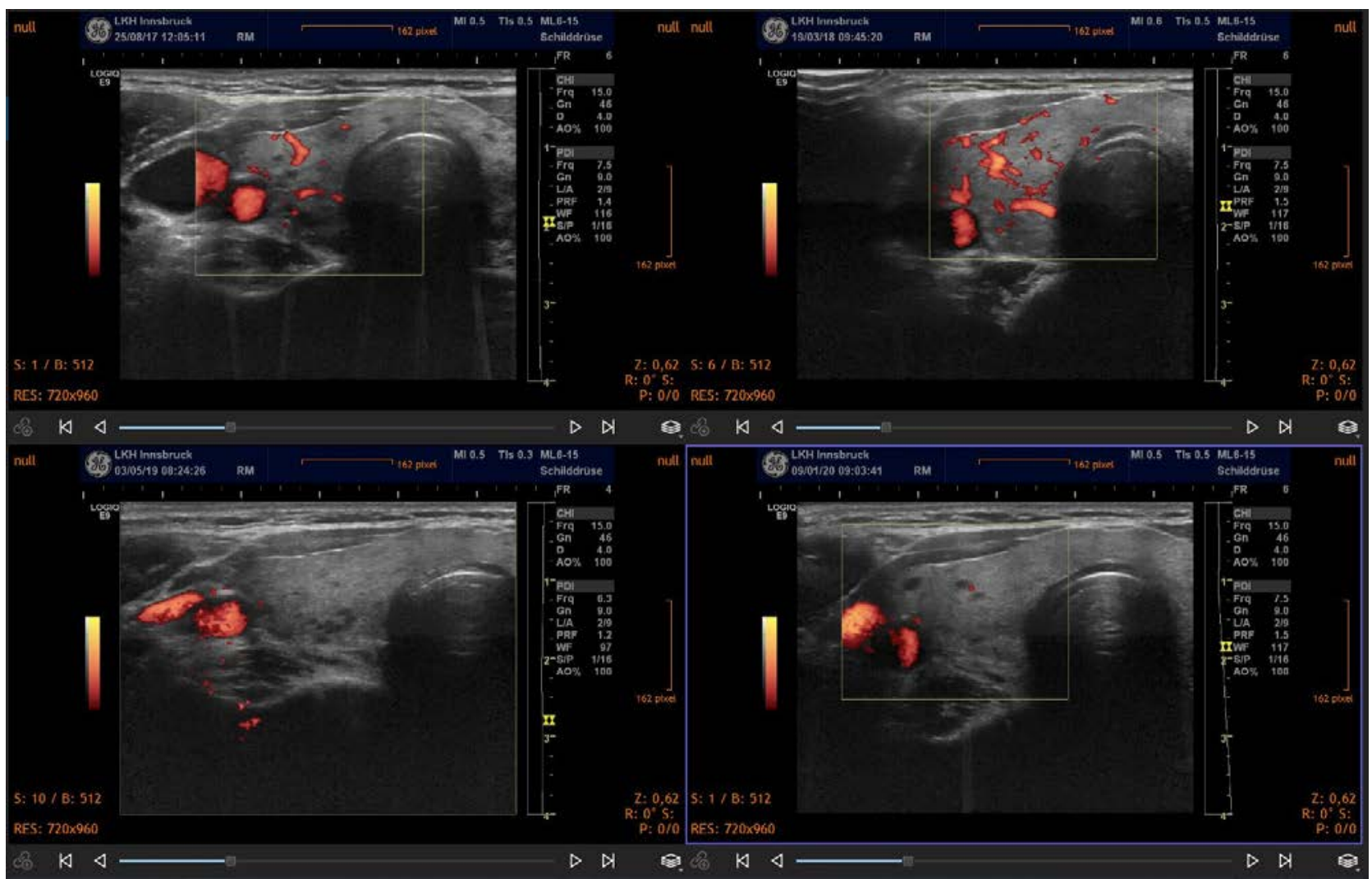

Figure 2. Sequential demonstration of normalization of thyroid perfusion in a case of Grave's disease. The initial studies (upper panel) revealed enlarged vessels which correspond to CoQ10 deficiency. Following supplementation vascularization returned to normal.

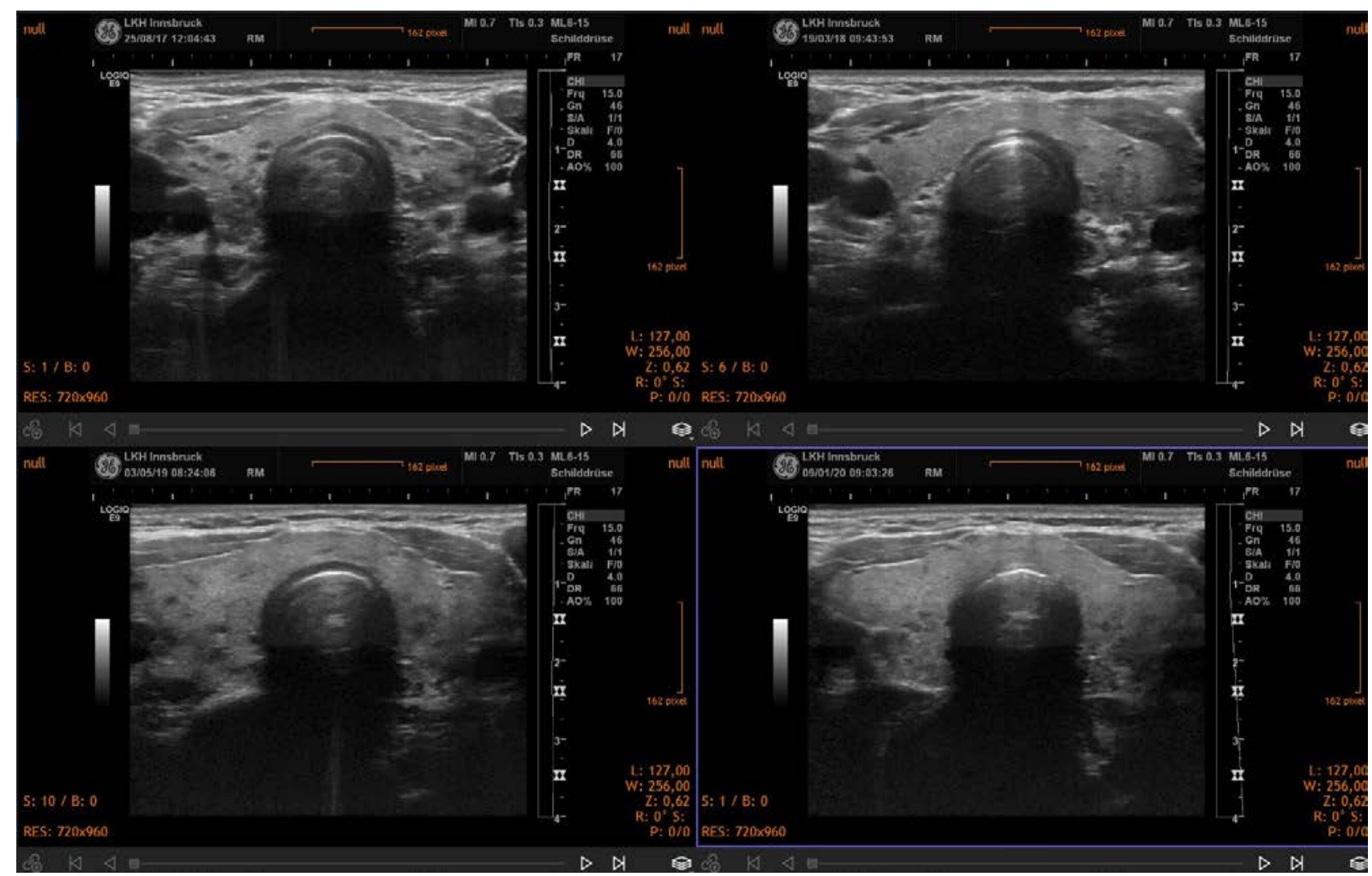

Figure 3. Sequential demonstration of partial normalization of thyroid morphology in a case of Grave's disease 


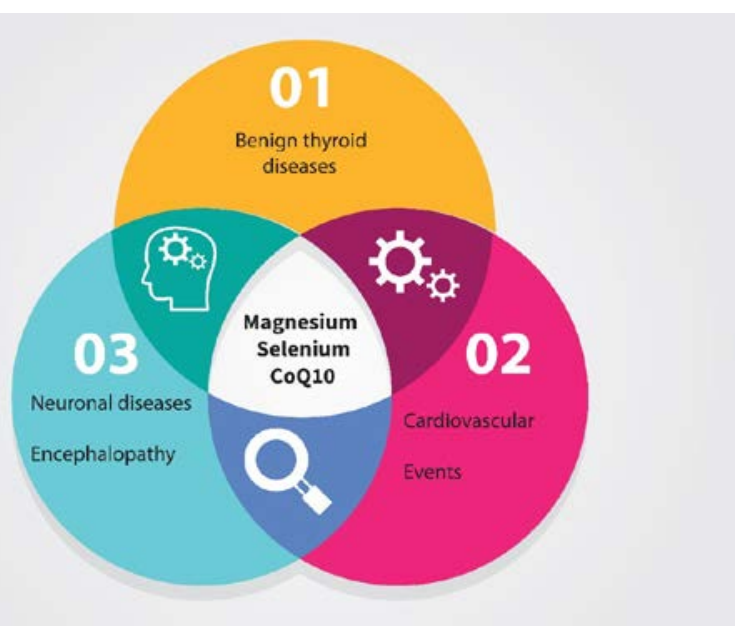

Figure 4. Venn diagram illustrating our concept of Shared Resources for different physiological systems

\section{Author's contributions}

$\mathrm{HM}$ and RM have developed the clinical working model and sonography methods. JR evaluated the citations contained in the Cochrane citations. RM wrote the manuscript. Figure 4 was adapted by RM using a template for Adobe Illustrator.

\section{References}

1. Gerschman R, Gilbert DL, Nye SW, Dwyer P, Fenn WO (1954) Oxygen poisoning and $\mathrm{x}$-irradiation: a mechanism in common. Science 119: 623-626. [Crossref]

2. Harman D (1956) Aging: a theory based on free radical and radiation chemistry. $J$ Gerontol 11: 298-300. [Crossref]

3. Balch WE, Morimoto RI, Dillin A, Kelly JW (2008) Adapting proteostasis for disease intervention. Science 319: 916-919. [Crossref]

4. Clausen L, Abildgaard AB, Gersing SK, Stein A, Lindorff-Larsen K, et al. (2019) Protein stability and degradation in health and disease. Adv Protein Chem Struct Biol 114: 61-83. [Crossref]

5. Henning RH, Brundel BJJM (2017) Proteostasis in cardiac health and disease. Nat Rev Cardiol 14: 637-653. [Crossref]

6. Morshed SA, Davies TF (2020) Understanding Thyroid Cell Stress. J Clin Endocrino Metab 105: pii: dgz193. [Crossref]

7. Hashimoto H (1912) Zur Kenntniss der lymphomatösen Veränderung der Schilddrüse (Struma lymphomatosa). Arch. Klin. Chir 97: 219-248.

8. Pichler R, Wölfl S, Bogner S, Sulzbacher H, Shamiyeh, et al. (2002) Subacute thyroiditis with cell destruction and temporary hyperthyroidism in Graves' diseasecase report. Acta Med Austriaca 29: 137-140. [Crossref]

9. Ciampolillo A, Guastamacchia E, Amati L, Magrone T, Munno I, et al (2003) Modifications of the immune responsiveness in patients with autoimmune thyroiditis: evidence for a systemic immune alteration. Curr. Pharm. Des 9: 1946-1950. [Crossref]

10. Moncayo R, Moncayo H (2015) Proof of concept of the WOMED model of benign thyroid disease: Restitution of thyroid morphology after correction of physical and psychological stressors and magnesium supplementation. BBA Clin 3: 113-22. [Crossref]
11. Moncayo R, Moncayo H (2015) The WOMED model of benign thyroid disease: acquired magnesium deficiency due to physical and psychological stressors relates to dysfunction of oxidative phosphorylation. BBA Clin 3: 44-64. [Crossref]

12. Balchin D, Hayer-Hartl M, Hartl FU (2016) In vivo aspects of protein folding and quality control. Science 353: aac4354. [Crossref]

13. Meyer T, Voigt N (2017) In search for novel functions of adenosine 5'-triphosphate (ATP) in the heart. Cardiovasc Res 113: e59-e60. [Crossref]

14. Patel A, Malinovska L, Saha S, Wang J, Alberti S, et al. (2017) ATP as a biologica hydrotrope. Science 356: 753-756. [Crossref]

15. Brown DA, Perry JB, Allen ME, Sabbah HN, Stauffer BL, et al (2017) Mitochondrial function as a therapeutic target in heart failure. Nat Rev Cardiol 14: 238-250. [Crossref]

16. van Zuuren EJ, Albusta AY, Fedorowicz Z, Carter B, Pijl H (2013) Selenium supplementation for Hashimoto's thyroiditis. Cochrane Database Syst Rev 6: CD010223. [Crossref]

17. Schomburg L (2011) Selenium, selenoproteins and the thyroid gland: interactions in health and disease. Nat Rev Endocrinol 8: 160-171. [Crossref]

18. Alehagen U, Johansson P, Björnstedt M, Rosén A, Dahlström U (2012) Cardiovascular mortality and N-terminal-proBNP reduced after combined selenium and coenzyme Q10 supplementation: A 5-year prospective randomized double-blind placebo-controlled trial among elderly Swedish citizens. Int. J. Cardiol 167: 1860-1866. [Crossref]

19. Mortensen SA, Rosenfeldt F, Kumar A, Dolliner P, Filipiak KJ, et al. (2014) The effect of coenzyme Q10 on morbidity and mortality in chronic heart failure: results from Q-SYMBIO: a randomized double-blind trial. JACC Heart Fail 2: 641-649. [Crossref]

20. Alehagen U, Alexander J, Aaseth J (2016) Supplementation with Selenium and Coenzyme Q10 Reduces Cardiovascular Mortality in Elderly with Low Selenium Status. A Secondary Analysis of a Randomised Clinical Trial. PLoS One 11: e0157541. [Crossref]

21. Alehagen U, Johansson P, Bjornstedt M, Rosen A, Post C, et al. (2016) Relatively high mortality risk in elderly Swedish subjects with low selenium status. Eur J Clin Nutr 70: 91-96. [Crossref]

22. Alehagen U, Aaseth J, Alexander J, Svensson E, Johansson P, et al. (2017) Less fibrosis in elderly subjects supplemented with selenium and coenzyme Q10-A mechanism behind reduced cardiovascular mortality? Biofactors 44: 137-147. [Crossref]

23. Alehagen U, Aaseth J, Alexander J, Johansson P (2018) Still reduced cardiovascular mortality 12 years after supplementation with selenium and coenzyme Q10 for four years: A validation of previous 10-year follow-up results of a prospective randomized double-blind placebo-controlled trial in elderly. PLoS One 13: e0193120. [Crossref]

24. Alehagen U, Aaseth J, Alexander J, Svensson E, Johansson P, et al. (2018) Less fibrosis in elderly subjects supplemented with selenium and coenzyme Q10-A mechanism behind reduced cardiovascular mortality? Biofactors 44: 137-147. [Crossref]

25. Alehagen U, Alexander J, Aaseth J, Larsson A (2019) Decrease in inflammatory biomarker concentration by intervention with selenium and coenzyme Q10: a subanalysis of osteopontin, osteoprotergerin, TNFr1, TNFr2 and TWEAK. $J$ Inflamm (Lond) 16: 5. [Crossref]

26. Alsafwah S, Laguardia SP, Arroyo M, Dockery BK, Bhattacharya SK, et al. (2007) Congestive heart failure is a systemic illness: a role for minerals and micronutrients. Clin. Med. Res 5: 238-243. [Crossref]

27. Madmani ME, Yusuf Solaiman A, Tamr Agha K, Madmani Y, Shahrour Y, et al. (2014) Coenzyme Q10 for heart failure. Cochrane Database Syst Rev 6 : CD008684. [Crossref]

Copyright: (C2020 Moncayo R. This is an open-access article distributed under the terms of the Creative Commons Attribution License, which permits unrestricted use, distribution, and reproduction in any medium, provided the original author and source are credited. 